\title{
Temporally Specific Burst in Cell Proliferation Increases Hippocampal Neurogenesis in Protracted Abstinence from Alcohol
}

\author{
Kimberly Nixon and Fulton T. Crews \\ Bowles Center for Alcohol Studies, The University of North Carolina at Chapel Hill, Chapel Hill, North Carolina 27599
}

\begin{abstract}
Adult neurogenesis is a newly considered form of plasticity that could contribute to brain dysfunction in psychiatric disease. Chronic alcoholism, a disease affecting over $8 \%$ of the adult population, produces cognitive impairments and decreased brain volumes, both of which are partially reversed during abstinence. Clinical data and animal models implicate the hippocampus, a region important in learning and memory. In a model of alcohol dependence (chronic binge exposure for $4 \mathrm{~d}$ ), we show that adult neurogenesis is inhibited during dependence with a pronounced increase in new hippocampal neuron formation after weeks of abstinence. This increase is attributable to a temporally and regionally specific fourfold increase in cell proliferation at day 7 of abstinence, with a majority of those cells surviving and differentiating at percentages similar to controls, effects that doubled the formation of new neurons. Although increases in cell proliferation correlated with alcohol withdrawal severity, proliferation remained increased when diazepam $(10 \mathrm{mg} / \mathrm{kg})$ was used to reduce withdrawal severity. Indeed, those animals with little withdrawal activity still show a twofold burst in cell proliferation at day 7 of abstinence. Thus, alcohol dependence and recovery from dependence continues to alter hippocampal plasticity during abstinence. Because neurogenesis may contribute to hippocampal function and/or learning, memory, and mood, compensatory neurogenesis and the return of normal neurogenesis may also have an impact on hippocampal structure and function. For the first time, these data provide a neurobiological mechanism that may underlie the return of human cognitive function and brain volume associated with recovery from addiction.
\end{abstract}

Key words: ethanol; dentate gyrus; adult neurogenesis; progenitor; addiction; neurotoxicity

\section{Introduction}

The discovery that neural stem-progenitor cells (NPCs) in the adult brain give rise to new neurons throughout life provides a novel way in which to consider neurodegeneration and recovery in psychiatric disorders (Armstrong and Barker, 2001). Adult neurogenesis from NPCs is well accepted in at least two brain regions: (1) the subventricular zone (SVZ) of the anterior lateral ventricles (Lois and Alvarez-Buylla, 1993) and (2) the subgranular zone (SGZ) of the hippocampal dentate gyrus (DG) (Altman and Das, 1965; Palmer et al., 1997). Adult neurogenesis is found in numerous species, including humans (Eriksson et al., 1998), and thousands of granule cells are generated daily in the rat dentate gyrus (Cameron and McKay, 2001). The functional role of adult-born neurons remains unclear but includes contributions to hippocampal learning and memory processes (van Praag et al., 1999b; Shors et al., 2001; Drapeau et al., 2003; Deisseroth et al.,

Received July 27, 2004; revised Sept. 14, 2004; accepted Sept. 14, 2004.

This research was supported by the National Institute on Alcohol Abuse and Alcoholism, the Alcoholic Beverage Medical Research Foundation, and the Bowles Center for Alcohol Studies. We gratefully acknowledge the technical contributions or advice of Silvia Bison, Andrew Kant, Daniel H. Kim, Thomas McCown, Erin Potts, and Ting Qian.

Correspondence should be addressed to Dr. Fulton T. Crews, Bowles Center for Alcohol Studies, The University of North Carolina at Chapel Hill, Thurston-Bowles Building, CB\#7178, Chapel Hill, NC 27599. E-mail: FTCrews@med.unc.edu.

D0I:10.1523/JNEUROSCI.3063-04.2004

Copyright $\odot 2004$ Society for Neuroscience $\quad 0270-6474 / 04 / 249714-09 \$ 15.00 / 0$
2004) and regulation of mood (Santarelli et al., 2003). Examination of brain dysfunction in psychiatric disease further supports a functional role of newborn neurons, because deficits in hippocampal integrity and behaviors correlate with decreased adult neurogenesis (Cameron and Gould, 1994; Eisch et al., 2000; Nixon and Crews, 2002; Santarelli et al., 2003).

Over 17 million Americans, or $8.5 \%$ of the population, meet the criteria for a diagnosis of alcohol dependence or alcohol abuse (Grant et al., 2004). Chronic alcoholics show a consistent pattern of cognitive deficits with noted impairments in spatial learning and memory, short term and declarative memory, and impulsivity, all of which suggest hippocampal dysfunction (Brandt et al., 1983; Parsons, 1993; Sullivan et al., 2000b). Observations of hippocampal neuropathology in human alcoholics (Bengochea and Gonzalo, 1990; Sullivan et al., 1995; Agartz et al., 1999; Laakso et al., 2000) are paralleled by descriptions of hippocampal cell loss and DG neurodegeneration in animal models (Walker et al., 1980; Collins et al., 1996; Obernier et al., 2002). Furthermore, alcohol intoxication decreases neurogenesis by inhibiting both NPC proliferation (Nixon and Crews, 2002; Rice et al., 2004) and newborn cell survival (Nixon and Crews, 2002; Herrera et al., 2003), effects that are consistent with cell loss in alcoholism. However, abstinence from alcohol in humans is associated with a reversal of neurodegeneration and return of cognitive ability, although the mechanism of this recovery is not clear (Carlen et al., 
1978; Harper, 1998). Indeed, improvements in learning and memory are associated with increased neurogenesis in rodent models (van Praag et al., 1999b). Only the effects of alcohol intoxication on adult neurogenesis have been investigated, thus prompting studies of neurogenesis during withdrawal and abstinence.

The development of alcohol dependence, or neural adaptation to chronic alcohol, includes several factors that regulate adult neurogenesis. Common features of alcohol dependence, particularly brain damage and seizures, reactively increase cell proliferation and neurogenesis (Hall and Zador, 1997; Crews et al., 2003). Thus, we hypothesized that neurogenesis may be differentially regulated during alcohol intoxication versus abstinence after alcohol dependence. This report describes for the first time a temporally specific increase in neurogenesis during abstinence after alcohol dependence.

\section{Materials and Methods}

Ethanol treatment. Eighty-one adult male rats (255-375 gm; Sprague Dawley; Charles River, Raleigh, NC) were used. All protocols followed the Guide for the Care and Use of Laboratory Animals by the National Research Council (1996) and were approved by the University of North Carolina Institutional Animal Care and Use Committee. Rats were maintained on a regular time $12 \mathrm{hr}$ light/dark cycle with ad libitum access to food and water except during ethanol exposure. Food was removed during the period of ethanol treatment, although water was freely available. Ethanol binge treatment was administered via gastric intubation following a procedure modified from Majchrowicz (1975) to maintain consistent, intoxicating blood ethanol levels while preventing mortality (Knapp and Crews, 1999; Nixon and Crews, 2002). In brief, rats were gavaged with an ethanol diet (25\% ethanol w/v in nutritionally complete diet; vanilla Ensure (Abbott Laboratories, Columbus, $\mathrm{OH}$ ) or isocaloric control diet every $8 \mathrm{hr}$ for $4 \mathrm{~d}$. After a priming dose of $5 \mathrm{gm} / \mathrm{kg}$, subsequent doses were determined using a six-point behavioral intoxication scale: 0 , normal rat; 1 , hypoactive; 2 , ataxia; 3 , ataxia with dragging abdomen and/or delayed righting reflex; 4 , loss of righting reflex; 5 , loss of eye blink reflex. Each score was associated with a dose of ethanol between 0 and 5 $\mathrm{gm} / \mathrm{kg}$. Blood ethanol concentrations were determined from tail blood samples drawn 90 min after the afternoon dose on the second day of the ethanol exposure period. Samples were centrifuged and then stored at $-20^{\circ} \mathrm{C}$ until analysis. Serum was extracted, and blood ethanol concentrations were measured by a GM7 Analyser (Analox, London, UK).

After the last dose of ethanol, food was replaced, and withdrawal behavior (Penland et al., 2001) (see also supplemental material, available at www.jneurosci.org) was observed from $10 \mathrm{hr}$ after the last dose $(T=10$ hr) through $T=24 \mathrm{hr}$. This period of time includes peak withdrawal behavior for this exposure model (Knapp et al., 1993; Penland et al., 2001).

Bromodeoxyuridine labeling. Bromodeoxyuridine (BrdU) (Sigma, St. Louis, MO) was dissolved in $0.9 \%$ saline $(20 \mathrm{mg} / \mathrm{ml})$ and administered ( $300 \mathrm{mg} / \mathrm{kg}$, i.p.) $4 \mathrm{hr}$ before the rats were killed by transcardial perfusion as a measure of cell proliferation. To examine a time course of changes in cell proliferation after ethanol exposure, BrdU was injected $4 \mathrm{hr}$ before the perfusion time points of day 0 ( $T=0 \mathrm{hr} ; 4 \mathrm{hr}$ before the last dose), day $3(T=72 \mathrm{hr})$, day $7(T=168 \mathrm{hr})$, day 14 , and day 28 . Perfusion time points were chosen based on the results of other studies (Parent et al., 1997; Liu et al., 1998). To examine changes in neurogenesis [BrdUpositive $(\mathrm{BrdU}+)$ cell survival and cell phenotype], a single dose of $\operatorname{BrdU}(300 \mathrm{mg} / \mathrm{kg}$, i.p.) was administered at $T=168 \mathrm{hr}$ (day 7), and rats were allowed to survive for an additional $28 \mathrm{~d}$ to day 35 , referred to as "day $7+28$ d."

Diazepam treatment. In a second experiment, a separate group of rats was examined for the effect of reduced withdrawal severity on cell proliferation at day 7. In a two $\times$ two design, control and ethanol-exposed rats received diazepam $(10 \mathrm{mg} / \mathrm{kg}$ ) or vehicle (two drops of Tween 20 quantum sufficit to $10 \mathrm{ml}$ with physiological saline) every $8 \mathrm{hr}$ for 24 hr. The $10 \mathrm{mg} / \mathrm{kg}$ dose of diazepam has been shown to significantly reduce epileptiform activity (Mhatre et al., 2001), alcohol withdrawal symptoms (Aaronson et al., 1982; Riihioja et al., 1997), and in the alcohol model used here, it specifically reduced withdrawal behaviors (Bone et al., 1989). At $T=10 \mathrm{hr}$, rats were injected with diazepam or vehicle and then observed for withdrawal behaviors until $T=24 \mathrm{hr}$. Because all rats were coded, observers were blind to the rat's experimental condition. All rats in this group were killed at day 7 (at $T=168$ ).

Immunohistochemistry. Animals were deeply anesthetized with ketamine and transcardially perfused as described previously (Knapp and Crews, 1999; Nixon and Crews, 2002). Coronal vibratome sections (40 $\mu \mathrm{m})$ were collected in a 1:12 series and stored in cryoprotectant at $-20^{\circ} \mathrm{C}$ until processing for immunohistochemistry. Sectioning began at a random start point in the caudate-putamen (approximately bregma 1.2 through bregma -7.0 ), which yielded tissue for the entire DG and included the SVZ.

For Ki-67 and doublecortin (DCX) immunohistochemistry, every 12th section was used, and standard immunohistochemistry procedures were followed, as described previously (Kee et al., 2002; Brown et al., 2003). Briefly, endogenous peroxidases were eliminated by incubation in $0.6 \% \mathrm{H}_{2} \mathrm{O}_{2}$ in TBS. Sections were blocked in TBS+ (TBS- $0.1 \%$ Triton$\mathrm{X}-3 \%$ normal serum) for $30 \mathrm{~min}$ and incubated at $4^{\circ} \mathrm{C}$ for $48 \mathrm{hr}$ in primary antibody diluted in TBS+ [mouse anti-Ki-67 diluted 1:200 (NCL-Ki67-MM1; Novacastra, Newcastle upon Tyne, UK); goat antiDCX diluted 1:400 (SC8066; Santa Cruz Biotechnology,Santa Cruz, CA)]. With washes between each step, the sections were incubated with appropriate biotinylated secondary antibody (horse anti-mouse or rabbit anti-goat; Vector Laboratories, Burlingame, CA) for $1 \mathrm{hr}$ followed by avidin-biotin-peroxidase complex (ABC Elite kit; Vector Laboratories) and detected with nickel-enhanced diaminobenzidine as a chromagen. Ki-67-labeled sections were lightly counterstained with neutral red, and all sections were coverslipped with mounting medium (Cytoseal; Stephens Scientific, Kalamazoo, MI).

Every sixth section was used for BrdU immunohistochemistry such that each section was $240 \mu \mathrm{m}$ apart. BrdU immunohistochemistry follows the methods of Kuhn et al. (1996) with an additional denaturing step, as reported previously (Nixon and Crews, 2002). Briefly, after denaturing and blocking in TBS + , free-floating sections were incubated in mouse anti-BrdU (MAB3424; Chemicon, Temecula, CA) diluted 0.25 $\mu \mathrm{g} / \mathrm{ml}$ in TBS+ and processed for the avidin-biotin-peroxidase reaction, as described previously (Nixon and Crews, 2002).

Quantification. Brains were coded so that the experimenter was blind to the experimental conditions during quantification procedures. For BrdU-labeled DG sections, the number of BrdU+ cells was counted in the granule cell layer and SGZ of the dorsal DG (bregma -1.8 to -5.8 ). The SGZ was defined as an $\sim 50 \mu \mathrm{m}$ ribbon between the granule cell layer and hilus. Cells were counted at $1200 \times$ with an oil immersion lens (Plan Apo $60 \times$ oil; numerical aperture, 1.4; Olympus Optical, Melville, NY). The area of the granule cell layer and SGZ was then obtained by tracing the region at $42.5 \times$ with image analysis software (Bioquant Nova Advanced Image Analysis; R\&M Biometric, Nashville, TN). In this profile counting methodology, cell counts were divided by the area of the section, expressed as cells $/ \mathrm{mm}^{2}$, and compared by ANOVA. We have shown previously that profile counting and stereological estimations show identical results in percentage change (Crews et al., 2004). In addition, BrdU+ cells are not a homogenously distributed population of cells; therefore, stereology may not be an appropriate method of quantification (Popken and Farel, 1997).

For the SVZ, BrdU immunoreactivity was determined with Bioquant image analysis software. Images were captured on an Olympus BX50 microscope and Sony (Tokyo, Japan) DXC-390 video camera at $42.5 \times$. Light levels were normalized to preset levels, and the microscope, camera, and software were background corrected to ensure reliability of image acquisition (Crews et al., 2004). The SVZ was outlined, and staining density was determined in pixels for the outlined area and expressed as pixels $/ \mathrm{mm}^{2}$.

Ki-67-positive (Ki-67+) cells were quantified using the profile counting methodology described above and expressed as cells $/ \mathrm{mm}^{2}$. DCX immunoreactivity (DCX-IR) in the granule cell layer and SGZ was also quantified with image analysis software (Bioquant). The granule cell layer and SGZ were traced, and staining density was determined by dividing the pixel count by the regional area and expressed as pixels $/ \mathrm{mm}^{2}$. 
Table 1. Alcohol intoxication statistics for the different time point groups in the proliferation time course experiment

\begin{tabular}{lll}
\hline $\begin{array}{l}\text { Perfusion time point } \\
\text { (days in abstinence) }\end{array}$ & $\begin{array}{l}\text { Blood ethanol concentration } \\
\text { (in milligrams per deciliter) }\end{array}$ & $\begin{array}{l}\text { Ethanol intake } \\
\text { (in grams per kilogram per day) }\end{array}$ \\
\hline Day 0 $(n=5)$ & $311.7 \pm 22.3$ & $\begin{array}{l}\text { Mean intoxication behavior } \\
\text { (scored every } 8 \text { hr) }\end{array}$ \\
Day 3 $(n=6)$ & $341.2 \pm 18.9$ & $9.1 \pm 0.5$ \\
Day $7(n=7)$ & $298.0 \pm 21.6$ & $8.5 \pm 0.4$ \\
Day 14 $(n=3)$ & $230.0 \pm 66.2$ & $9.1 \pm 0.8$ \\
Day 28 $(n=4)$ & $323.0 \pm 38.9$ & $9.3 \pm 1.6$ \\
\hline
\end{tabular}

Blood ethanol concentrations (2nd column) were measured from serum extracted from tail blood on the second day of chronic binge treatment and were similar for all proliferation time points. In addition, neither average ethanol intake per day ( 3 rd column) nor mean intoxication behavior (4th column) was different between groups for the proliferation time course. The similarity in intoxication parameters for all time points rules out effects of blood ethanol levels, ethanol dose, or intoxication behavior on cell proliferation.

${ }^{a}$ Day 0 in abstinence, 4 d of ethanol and killed at $T=0 \mathrm{hr}$.

Fluorescent immunohistochemistry. Triplefluorescence immunohistochemistry was performed on every 12 th section to determine cell differentiation in a manner similar to the one described previously (Kuhn et al., 1997). After DNA denaturing (without DNase), sections were blocked in TBS + for $1 \mathrm{hr}$ and incubated overnight at $4^{\circ} \mathrm{C}$ rat anti-BrdU (1:400; Accurate, Westbury, NY), mouse anti-NeuN (1:500; Chemicon), and rabbit anti-GFAP (1:2000; Dako, Glostrup, Denmark). After washes in TBS + , sections were incubated for $1 \mathrm{hr}$ in fluorescent-coupled secondary antibodies (Alexa Fluor goat anti-rat 488, Alexa Fluor goat anti-mouse 555, Alexa Fluor goat anti-rabbit 633; Molecular Probes, Eugene, OR) plus 1.5\% goat serum. Sections were washed in TBS, mounted and dried, then coverslipped with antifade mounting medium (Pro-Long; Molecular Probes). The colocalization of BrdU to neuronspecific [neuronal-specific nuclear protein $(\mathrm{NeuN})]$ or glia-specific (GFAP) proteins was confirmed by confocal microscopy optimized for the analysis of tissue sections. Specifically, a Zeiss (Oberkochen, Germany) Axiovert LSM510 confocal microscope was used on multitrack setting with a water immersion lens (C-Apochromat $40 \times / 1.2 \mathrm{~W}$ corr). For each subject, $50 \mathrm{BrdU}+$ cells were analyzed for colocalization with $\mathrm{NeuN}$ or GFAP and reported as a percentage of the number of BrdU+ cells. The 50 cells were selected from several fields in a minimum of five tissue sections. $Z$-plane section images $(512 \times 512$ pixels $)$ were collected at $<1 \mu \mathrm{m}$ thickness and then analyzed using LSM Image Examiner software (Zeiss). The criteria for colabeling included appropriate morphology and more than two Z-plane images of copositive staining. Values of "calculated neurogenesis" were computed by multiplying the differentiation percentages by the number of BrdU + cells at day $35($ day $7+28 \mathrm{~d})$. The number of BrdU + cells at day 35 was counted at $400 \times$ in the same sections using a fluorescent microscope (Olympus BX-51 microscope with FITC filter cube) and expressed as the number of cells per section.

Statistical analysis. Statistical analyses were conducted in StatView (Mac version 5.0.1; Abacus Concepts, Berkeley, CA). All cell counts, blood ethanol measurements, and immunoreactivity measures were analyzed by ANOVA. For cell counts and immunoreactivity measures, additional post hoc analyses were planned $t$ tests or Tukey-Kramer (experiment 2). Noncontinuous behavioral measures were analyzed by nonparametric Mann-Whitney $U$ tests. Seizure severity classifications were compared by $\chi^{2}$. In all cases, differences were considered significant at the $p<0.05$ level. All values were reported as mean \pm SEM.

\section{Results}

\section{Cell proliferation during ethanol dependence, withdrawal,} and abstinence

To investigate the effects of alcohol dependence on the components of adult neurogenesis, ethanol was administered in a chronic $4 \mathrm{~d}$ binge model followed by BrdU administration to label dividing cells. The amount of ethanol administered over $4 \mathrm{~d}$ averaged $8.9 \pm 0.2 \mathrm{gm} / \mathrm{kg}$ per $\mathrm{d}$, an amount that is similar to that consumed in rodent self-administration models (Lukoyanov et al., 2000). BrdU labeling of cell proliferation was investigated at several time points after the last dose of ethanol: day 0 (at $T=0$ hr), day 3 (at $T=72 \mathrm{hr}$ ), day 7 (at $T=168 \mathrm{hr}$ ), day 14 , and day 28 . All groups were comparable in ethanol intoxication as assessed by blood ethanol concentrations, ethanol intake, and intoxication behavior (Table 1). BrdU+ cells were visible along the DG in all groups and typically as either clusters or doublets of irregularshaped cells along the SGZ of both blades of the DG (Fig. 1). Changes in the number of BrdU + cells between ethanol-exposed and control rats were apparent at specific time points (significant interaction time point by treatment group; factorial ANOVA; $F_{(4,38)}=3.706 ; p<0.01$ ). At day 0 (Fig. 1 ), a time point that immediately followed the last dose of ethanol, the number of BrdU + cells was decreased by $48 \%$ in ethanol-treated rats $(n=5)$ relative to controls ( $p$ ost hoc planned $t$ test; $p<0.01 ; n=6$ ). Notably, rats were still visibly intoxicated and likely had $>200$ $\mathrm{mg} / \mathrm{dl}$ blood ethanol concentrations at this time point predicted by their intoxication behaviors scored immediately before their last dose of ethanol (Majchrowicz, 1975; Knapp and Crews, 1999). At day 3 of abstinence, the number of BrdU+ cells in 


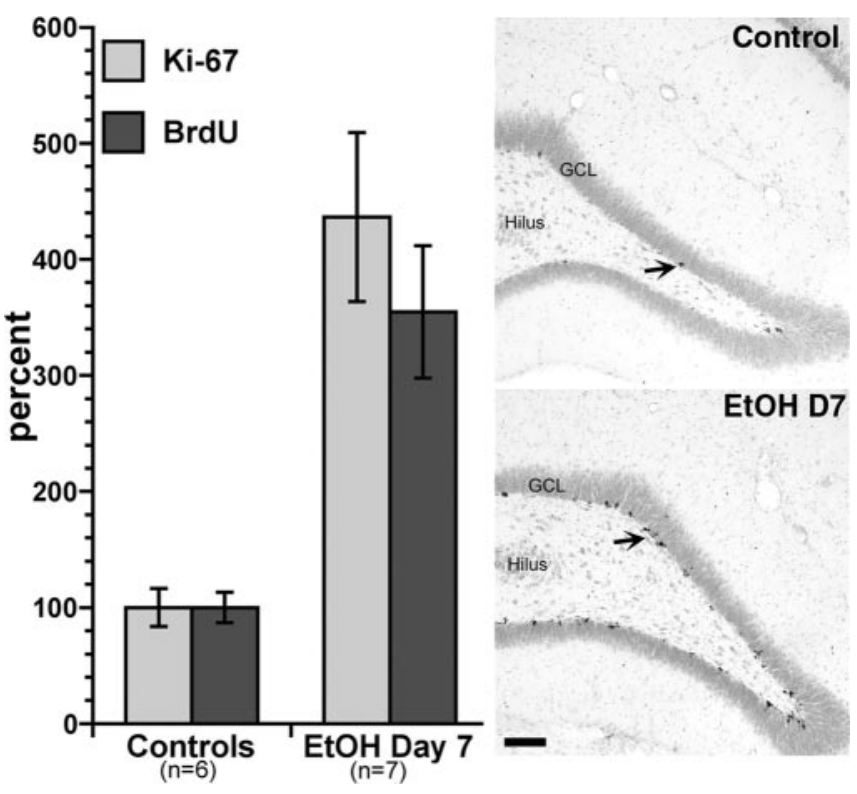

Figure 2. Comparison of cell proliferation markers at day 7 of abstinence. Because BrdU incorporation could be altered by bioavailability, the increase in cell proliferation at day 7 was confirmed with Ki-67 immunohistochemistry. In ethanol-exposed rats (EtOH), both BrdU and Ki-67 immunohistochemistry increased by similar percentages versus controls. Error bars represent SEM. Representative photomicrographs of Ki-67-stained sections show the increased number of actively dividing cells (arrows) along the border of the granule cell layer (GCL) and subgranular zone in the alcohol group (EtOH D7) versus controls. Scale bar, $100 \mu \mathrm{m}$.

ethanol-exposed animals $(n=5)$ returned to control $(n=6)$ levels. However, at day 7 of abstinence, the number of BrdU+ cells in the ethanol-exposed group $(n=7)$ was $350 \%$ of controls $(p<0.05 ; n=6)$. By day 14 (control, $n=4$; ethanol, $n=3$ ) and day 28 (control, $n=6$; ethanol, $n=4$ ) of abstinence, the number of BrdU + cells was similar between ethanol-exposed and control groups. Thus, ethanol intoxication decreased cell proliferation, which was reversed early in abstinence, followed by a dramatic increase in proliferation 1 week after the last dose of ethanol.

To confirm the increase in hippocampal cell proliferation at day 7 found with the exogenous cell proliferation marker BrdU, an adjacent set of sections was stained for an endogenous marker of proliferating cells, Ki-67 (Kee et al., 2002). Ki-67 labels all actively cycling cells although not cells in $\mathrm{G}_{0}$ phase, the resting state (Kee et al., 2002). At day 7, the number of Ki-67+ cells was $350 \%$ higher $\left(F_{(1,10)}=14.377 ; p<0.01\right)$ in ethanol-exposed rats $\left(366.8 \pm 61.3\right.$ cells $\left./ \mathrm{mm}^{2} ; n=7\right)$ than controls $(84.0 \pm 13.7$ cells $\left./ \mathrm{mm}^{2} ; n=5\right)$. This fourfold increase in proliferation was similar to the increase in proliferation shown by the exogenous BrdU label (Fig. 2).

To examine whether cell proliferation was altered in another brain region where it is well established that neurogenesis occurs, BrdU immunoreactivity was quantified in the SVZ at day 7. A line of BrdU + cells was clearly noted along the SVZ of both treatment groups; BrdU immunoreactivity was $5043.0 \pm 730.9$ pixels $/ \mathrm{mm}^{2}$ in controls $(n=4)$ versus $5995.6 \pm 818.3$ pixels $/ \mathrm{mm}^{2}$ in ethanoltreated rats $(n=6 ; p>0.05)$. Thus, 1 week into abstinence from ethanol, cell proliferation is specifically increased in the DG but not in the SVZ.

\section{Increased neurogenesis in abstinence}

To determine whether this increase in cell proliferation also produced an increase in neurogenesis (i.e., the formation of new neurons), a neuronal marker expressed shortly after cell fate de- termination, DCX, was examined by immunohistochemistry. DCX is expressed by migrating neuroblasts several days after cells divide (Gleeson et al., 1999; Brown et al., 2003). Therefore, if the cell proliferation event observed at day 7 is followed by an increase in neurogenesis, DCX expression should be evident several days after the day 7 time point. As shown in Figure 3, DCX-IR was similar between ethanol-exposed rats and controls at day 7 (control, $n=5$; ethanol, $n=7$ ) and day 28 (control, $n=6$; ethanol, $n=6)$. However, at day 14, DCX-IR was increased twofold in the ethanol-exposed rats $(n=4)$ versus controls $(n=4)$, as indicated by a significant interaction of time point-by-treatment group factorial ANOVA $\left(F_{(2,25)}=11.872 ; p<0.001\right)$ and planned post hoc $t$ tests $(p<0.05)$. Thus, as would be expected for delayed expression of DCX, 1 week after the burst in cell proliferation at day 7 (i.e., 2 weeks after the last dose of ethanol), there is an increase in DCX in the DG.

In the DG granule cell layer, the newborn cells that survive $28 \mathrm{~d}$ are stably incorporated into the granule cell layer (Kempermann et al., 2003). Therefore, we investigated long-term changes in neurogenesis by analyzing cell fate and phenotype at day 35, which is $28 \mathrm{~d}$ after the burst in proliferation at day 7 (Fig. 4). For this study, BrdU was administered on day 7 of abstinence, and the animals were allowed to survive for 28 additional days, a time at which most cells have differentiated. Figure 5 shows that on day 35 (day $7+28 \mathrm{~d}$ ), the number of BrdU + cells is twofold higher in ethanol-exposed animals $(n=5)$ than controls $\left(n=6 ; F_{(1,10)}=\right.$ $22.360 ; p<0.01)$. Visual inspection indicated that the shape, size, and distribution of BrdU+ nuclei throughout the granule cell layer of the DG were similar between treatment groups. BrdU+ cells were examined for colabeling with a neuron-specific protein $(\mathrm{NeuN})$ or a glia-specific protein (GFAP). In the ethanol-exposed animals $(n=5), 82.7 \pm 3.5 \%$ of BrdU+ cells colabeled with NeuN and $7.5 \pm 3.5 \%$ colabeled with GFAP. These percentages were similar to control animals $(n=6)$ in which $81.9 \pm 2.5 \%$ of $\mathrm{BrdU}+$ cells colabeled with NeuN and $8.2 \pm 2.7 \%$ colabeled with GFAP and also similar to percentages that have been reported previously (van Praag et al., 1999a; Eisch et al., 2000). When these percentages are multiplied by the number of BrdU+ cells, neurogenesis can be calculated and compared between the two groups (Fig. 5). As such, the number of new neurons labeled with BrdU and NeuN is higher in the ethanol-treated animals than controls $\left(F_{(1,9)}=16.984 ; p<0.01\right)$. In addition, the number of BrdU + cells that did not label for either NeuN or GFAP is increased in ethanol-exposed rats versus controls $\left(F_{(1,9)}=8.719\right.$; $p<0.05)$. Thus, cell differentiation was not altered during abstinence from ethanol. However, the number of BrdU+ cells and calculated new neurons was greatly increased $28 \mathrm{~d}$ after the burst in cell proliferation observed on day 7 of abstinence.

\section{Assessing role of withdrawal in cell proliferation}

Anticipating that withdrawal may play a role in ethanol-induced changes in neurogenesis, withdrawal behaviors were scored during a previously determined peak between $T=10$ and $T=24 \mathrm{hr}$ (i.e., between day 0 and day 1) (Majchrowicz, 1975; Knapp et al., 1993; Penland et al., 2001). Rats displayed the full range of withdrawal behaviors. For all rats used in the first experiment, the average withdrawal score over time ( $14 \mathrm{hr}$ ) was $1.8 \pm 0.2$, whereas the peak score, or highest score achieved, averaged $3.5 \pm 0.1$. To gain insight into the possible mechanism underlying the increase in cell proliferation observed at day 7 of abstinence, Pearson product moment correlations were determined for the number of BrdU + cells at day 7 versus several behavioral and treatment measures collected for each animal during the course of the ex- 
periment. Of the various parameters investigated for correlations with day 7 cell proliferation (dose of ethanol per day, intoxication behavior, weight loss, blood ethanol concentrations, and peak withdrawal behavior), only mean withdrawal score (at day 0) showed a significant positive correlation $(r=0.84 ; p<0.05)$ to an increased number of BrdU+ cells at day 7 . Thus, as the mean withdrawal score (but not peak withdrawal score) increased, the number of BrdU+ cells at day 7 also increased.

Because withdrawal severity correlated with the number of BrdU+ cells at day 7, we performed a second experiment to address whether reducing withdrawal severity would prevent the burst in cell proliferation at day 7 . This second group of rats was subjected to chronic binge ethanol exposure followed by diazepam [3 $\times 10 \mathrm{mg}$ / $\mathrm{kg}$, i.p. every $8 \mathrm{hr}$ for the first day (i.e., day 0 -day 1)] to reduce withdrawal symptoms (Aaronson et al., 1982; Bone et al., 1989; Riihioja et al., 1997). As with the first experiment, rats were then injected with BrdU (300 mg/kg) $4 \mathrm{hr}$ before they were killed on day 7 (at $T=168 \mathrm{hr}$ ). To confirm that diazepam reduced the severity of withdrawal behavior, we compared all withdrawing animals used in this report (ethanol alone and ethanol plus vehicle; total $n=31$ ) to a group of animals receiving ethanol plus diazepam $(n=13)$ by three different measures: mean withdrawal score, peak withdrawal score, and classifying withdrawal severity (Majchrowicz, 1975). Both mean withdrawal scores $(U=83.0 ; p<0.01)$ and peak withdrawal scores $(U=107.0 ; p=0.01)$ were significantly decreased in the ethanol plus diazepam group compared with ethanolethanol plus vehicle group shown in Table 2. Indeed, a low withdrawal severity group clearly stood out among the rats, as has been described previously (Majchrowicz, 1975). Typically, between 10 and $15 \%$ of binge ethanol-exposed rats showed few withdrawal signs (described as less than three withdrawal signs by Majchrowicz), so we then classified the rats into two groups similar to Majchrowicz's original work (1975). Any animal with a behavior score of $<0.8$ and fewer than three withdrawal signs (Majchrowicz, 1975) was designated as "low withdrawal." Because the animals were coded, the group designation was performed with the experimenter blind to the group of the animal. In the ethanolethanol plus vehicle group, $12.9 \%$ were in the low category, and the remaining $87.1 \%$ were in the moderate-high withdrawal category (Table 2), percentages that were similar to those reported by Majchrowicz (1975). Ethanol plus diazepam increased the percentage of rats classified as low withdrawal by over fourfold $\left(\chi^{2}=8.19 ; p<0.01\right)$. Thus, diazepam, by all measures analyzed, decreased the severity of withdrawal symptoms.
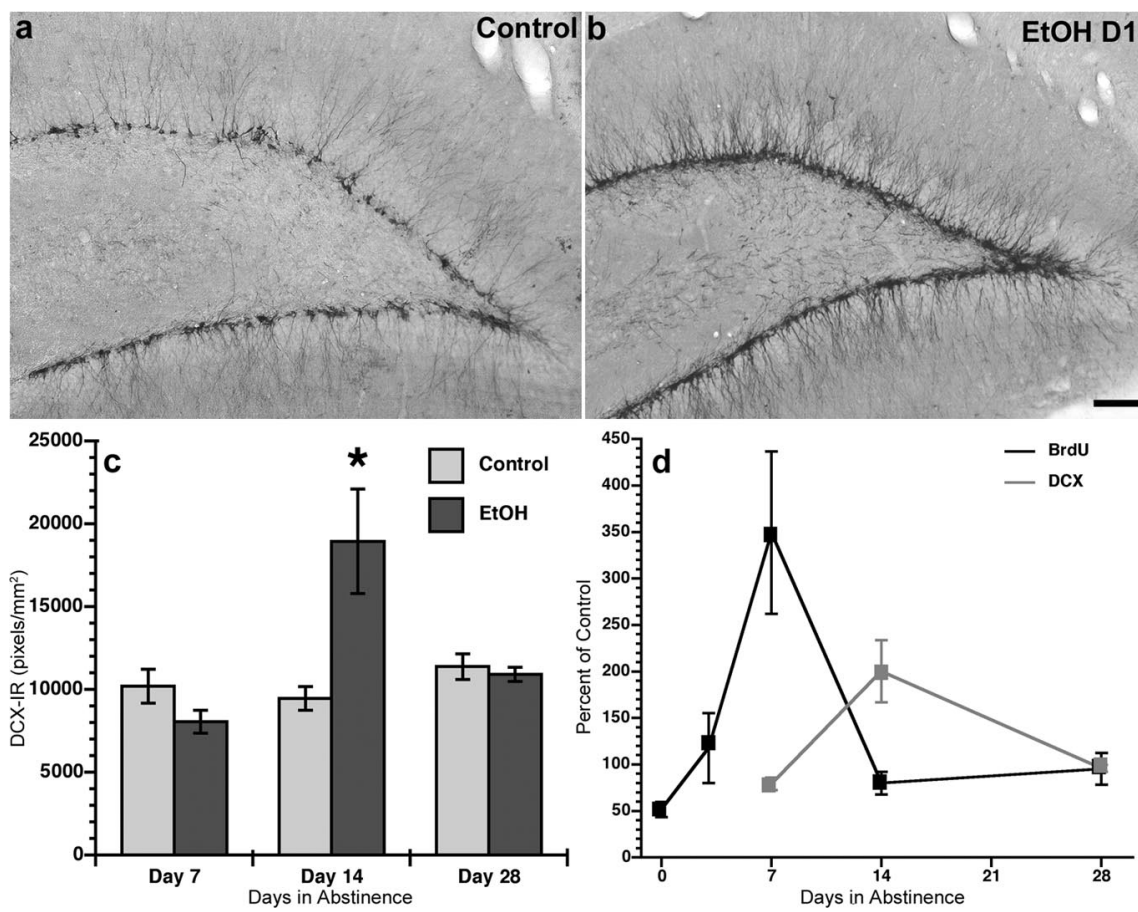

Figure 3. Doublecortin expression is altered during abstinence. DCX immunoreactivity is selectively increased 1 week after the increase in BrdU incorporation, as shown by representative photomicrographs of DCX-IR in the DG at day 14 from control $(a)$ and alcohol-exposed $(\mathrm{EtOH} ; b)$ rats. $c$, DCX-IR was significantly higher $(p<0.05)$ in the ethanol-exposed rats (EtOH; $n=4)$ than consistent with doublecortin expression labeling young migrating neuroblasts (Gleeson et al., 1999; Brown et al., 2003). Scale bar,
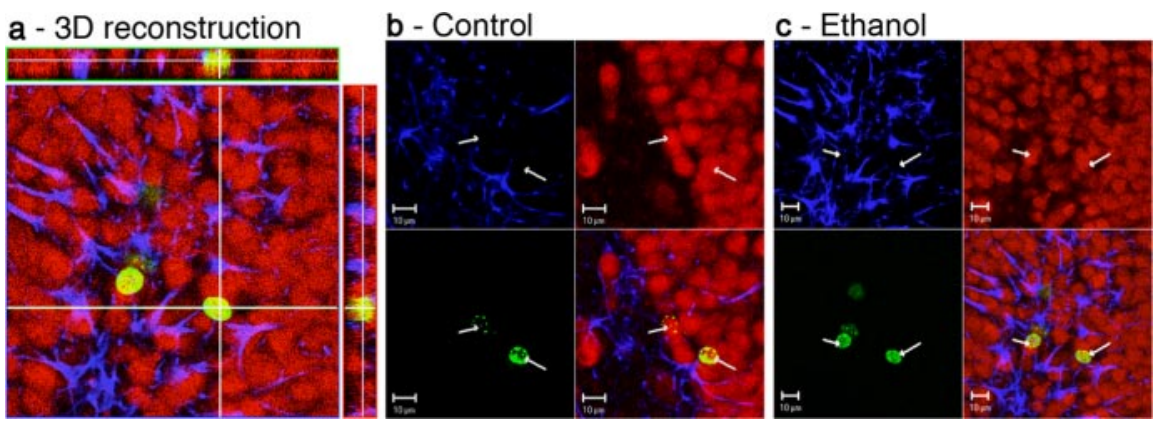

Figure 4. Determination of cell phenotype at day 35 (day $7+28 \mathrm{~d}$ ). Cell phenotype was determined by confocal microscopy of sections triple labeled for BrdU (green), NeuN (red), and GFAP (blue). $a$, For each brain, 50 BrdU + cells were Z-sectioned at $<1$ struction of a newborn neuron in yellow (i.e., NeuN in red colabeled with BrdU in green shows as yellow). Representative images of all three channels and the triple-labeled image for a control rat $(b)$ and an ethanol-treated $(\mathrm{EtOH})$ rat $(c)$ highlights the similarities in new neurons, as shown with arrows indicating the colabeling of BrdU and NeuN. Scale bars, $10 \mu \mathrm{m}$.

We then investigated cell proliferation in this second group of animals to assess whether reduced withdrawal symptoms would alter ethanol-induced increases in cell proliferation at day 7 . In all four groups (control plus vehicle, $n=6$; control plus diazepam, $n=8$; ethanol plus vehicle, $n=6$; and ethanol plus diazepam, $n=13)$, BrdU + cells were located along the SGZ-granule cell border in clusters. Overall, the number of BrdU+ cells in the DG was higher in both ethanol groups versus controls as shown by a significant main effect for treatment (ethanol vs control; two-way ANOVA; $\left.F_{(1,29)}=19.946 ; p<0.001\right)$. Post hoc analyses revealed that the number of BrdU + cells in both the ethanol $(n=6)$ and ethanol plus diazepam $(n=13)$ group was significantly increased compared with its appropriate control; however, as indicated by a 


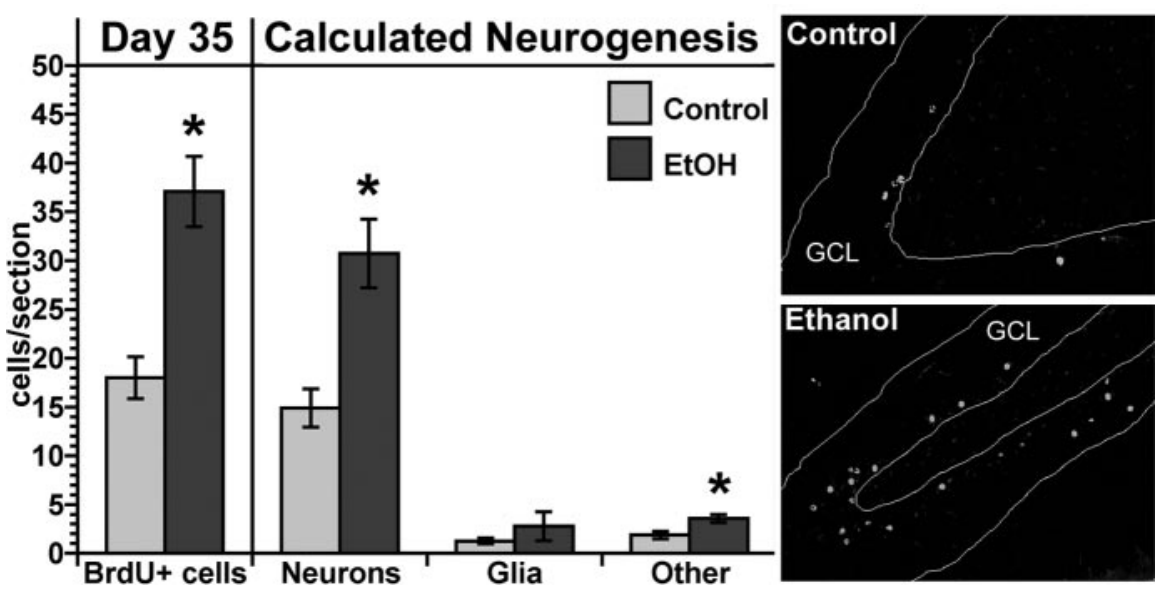

Figure 5. Increased neurogenesis at day 35 of abstinence. Although BrdU-labeled cells differentiated into neurons and glia similarly in each group (see Results), the number of BrdU + cells remained increased in ethanol-exposed rats (EtOH; $n=5$ ) versus controls ( $n=6$; left side of graph). When the differentiation percentages (e.g., $\sim 80 \%$ of BrdU cells colabel with NeuN) are applied to the BrdU+ cell counts (e.g., 37 cells/section), neurogenesis can be calculated (e.g., 30 new neurons; shown on right side of graph). Thus, neurogenesis is increased in ethanol-exposed rats $28 \mathrm{~d}$ after BrdU-incorporation at day 7. Error bars represent SEM. Representative fluorescent images of BrdU + cells in the DG at day 35 (day $7+28 \mathrm{~d}$ ) for control and ethanol-exposed (EtOH) rats clearly shows the greater number of BrdU + cells along the granule cell layer (outlined). GCL, Granule cell layer. * $p<0.05$.

lack of statistical interaction, the ethanol plus vehicle group and ethanol plus diazepam group were statistically similar (Fig. 7). Also, both control groups were similar; diazepam $(n=8)$ alone did not produce an increase in BrdU + cells relative to control plus vehicle rats $(n=6)$. In summary, cell proliferation remains high despite diazepam treatment to reduce withdrawal severity. Interestingly, when the animals classified in the low withdrawal group were analyzed separately, both alcohol groups [ethanol plus vehicle $(n=2)$ and ethanol plus diazepam $(n=7)]$ showed a twofold increase versus combined controls $(n=14)$ yet were similar to each other (one-way ANOVA; $F_{(2,25)}=6.883 ; p<0.01$; post hoc $p<0.05)$. Thus, even in the low withdrawal severity conditions, cell proliferation is significantly higher in the ethanol-exposed animals than controls at day 7 of abstinence.

\section{Discussion}

This study is the first to show that chronic ethanol continues to alter neurogenesis in the adult rat hippocampus weeks after the cessation of ethanol. Specifically, we report for the first time that neurogenesis was increased over twofold at 5 weeks into abstinence. Alcohol dependence induced a fourfold burst in cell proliferation at day 7 of abstinence that is specific to the dentate gyrus SGZ, a region containing NPCs. After the burst in cell proliferation, evidenced by increased BrdU-labeled cells, was an increase in DCX-IR at day 14. This increase in DCX-IR lagged 1 week behind the increase in cell proliferation (Fig. 3), which suggests that alcohol dependence also increased neurogenesis. Furthermore, we observed that the cells produced at day 7 survive at least $28 \mathrm{~d}$, such that the number of BrdU+ cells remains increased at day 35. Analysis of cell phenotype at day 35 (day $7+28 \mathrm{~d}$ ) showed that the newborn cells in the ethanol-exposed animals differentiated similar to controls. Thus, neurogenesis was increased at 5 weeks in abstinence and was likely attributable to the burst in cell proliferation at day 7 . Together, the data suggest that ethanol decreases neurogenesis during intoxication, consistent with our previous work (Nixon and Crews, 2002), and as we report for the first time, ethanol increases neurogenesis during abstinence after alcohol dependence.

Because altered BrdU labeling could be attributed to BrdU bioavailability, we performed two experiments on the day 7 group to verify increased cell proliferation: (1) assessment of BrdU labeling in the SVZ and (2) examination of an endogenous cell proliferation marker, Ki-67, in the DG. At day 7, no changes in BrdU labeling were noted in the SVZ; thus, cell proliferation in the frontal neurogenic region appears unchanged by alcohol dependence at this time point. Also at day 7, the number of Ki-67-labeled cells in the DG was increased fourfold in ethanol-exposed animals, similar to the pattern of BrdU labeling (Fig. 2). Because Ki-67 labels all actively dividing cells, and Ki-67 is increased at day 7, this suggests that additional cells were recruited into active cycling (Scholzen and Gerdes, 2000; Kee et al., 2002).

NPC proliferation and neurogenesis are regulated by many factors, including several that are common to chronic alcoholism [Crews et al. (2003), their Fig. 3]. The second experiment addressed the "alcohol withdrawal syndrome," a range of behavioral and physiological signs that occur in alcoholdependent individuals after the cessation of drinking (Hall and Zador, 1997). Overt withdrawal signs such as tremors and seizures are evidence of "CNS hyperexcitability," which results from neural adaptations to chronic alcohol (De Witte et al., 2003). Because seizures result in increased NPC proliferation and aberrant neurogenesis (Parent et al., 1997), we examined alcohol withdrawal severity and seizure behaviors as factors underlying increased neurogenesis after alcohol dependence. Although alcohol withdrawal severity was correlated with increased BrdU+ cells at day 7, when we reduced withdrawal severity with diazepam, cell proliferation remained increased. Interestingly, when low withdrawal severity groups were analyzed separately (Fig. 7), cell proliferation remained significantly higher in these animals with few overt withdrawal signs. However, it is possible that changes in psychological stress or other factors, such as diet changes, contribute to increased cell proliferation after ethanol administration. Stress and glucocorticoids reduce neurogenesis (Cameron and Gould, 1994), and binge ethanol treatment elevates glucocorticoids during intoxication, although levels return to control values after withdrawal (Jerrells et al.,1990). Furthermore, caloric restriction increases neurogenesis but not by altering cell proliferation (Lee et al., 2002), and our diet is nutritionally complete and calorically matched between treatment groups. No studies have reported a delayed effect of stress or nutrients on cell proliferation, so these sequelae associated with human alcoholism and animal models of alcoholism cannot be ruled out. Thus, we concluded that although withdrawal severity and seizures may contribute in part to increased cell proliferation, alcohol dependence results in a profound increase in neurogenesis during abstinence.

A major element of CNS hyperexcitability is glutamate transmission, specifically, increased glutamate levels in the hippocampus during alcohol withdrawal (Rossetti and Carboni, 1995; Dahchour and De Witte, 1999). However, activation of the glutamatergic NMDA receptor (NMDAR) decreases cell proliferation in the DG (Cameron et al., 1995). CNS hyperexcitability also wanes at $24 \mathrm{hr}$ of withdrawal, and our finding of increased 
Table 2. Diazepam reduces withdrawal severity

\begin{tabular}{llll}
\hline & Mean WD score & Peak WD score & Moderate- high WD \\
\hline EtOH-EtOH plus vehicle $(n=31)$ & $1.6 \pm 0.2$ & $3.4 \pm 0.1$ & $12.9 \%(n=4)$ \\
EtOH plus diazepam $(n=13)$ & $0.71 \pm 0.2^{*}$ & $2.6 \pm 0.3^{*}$ & $87.1 \%(n=27)$ \\
\hline
\end{tabular}

Beginning at $10 \mathrm{hr}$ after the last dose of alcohol, rats were administered diazepam $(10 \mathrm{mg} / \mathrm{kg}$, i.p.) every $8 \mathrm{hr}$ to reduce withdrawal severity. This dose reduces both epileptiform activity as measured by spike wave discharge (Mhatre et al., 2001) as well as seizure-like withdrawal symptoms (Bone et al., 1989). Both mean withdrawal (WD) scores and peak withdrawal scores were reduced with diazepam treatment. In addition, diazepam reduced the percentage of rats classified with moderate or severe withdrawal symptoms, thus increasing the number of rats classified with low withdrawal symptoms. Et0H, Ethanol treated. ${ }^{*} p<0.05 ;{ }^{* *} \chi^{2}=8.19, p<0.01$.
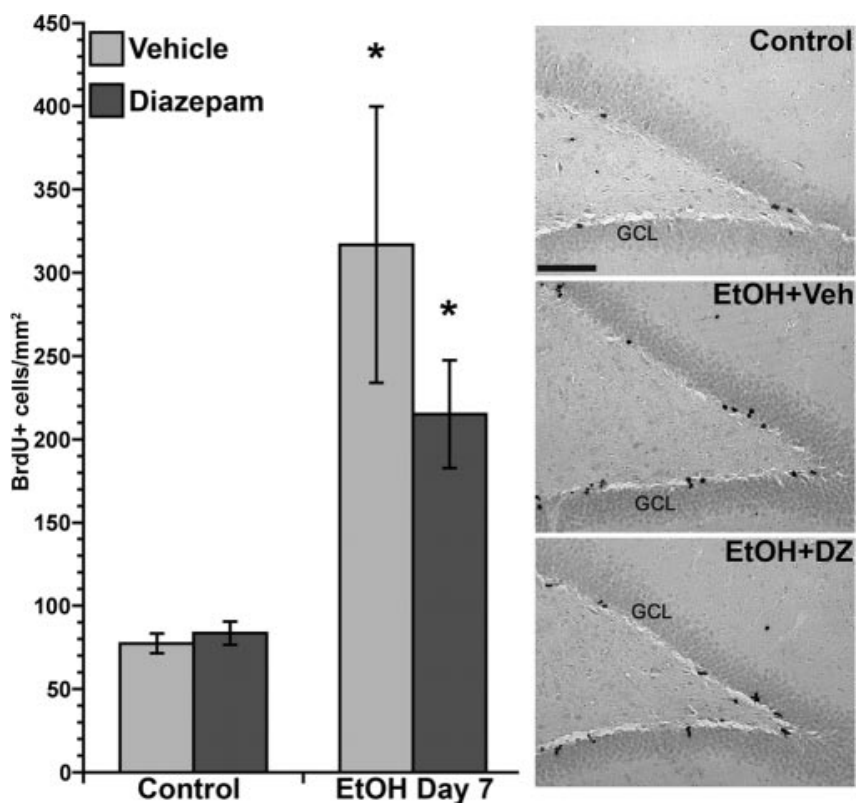

Figure 6. Increased cell proliferation persists regardless of withdrawal severity. Reduction of withdrawal severity did not reduce cell proliferation to control levels in ethanol-exposed rats (EtOH). Diazepam (DZ; $10 \mathrm{mg} / \mathrm{kg}$ ) was injected every $8 \mathrm{hr}$ from $T=10$ through $T=24 \mathrm{hr}$ to reduce withdrawal severity. The number of BrdU + cells remained increased versus controls, despite reduction of withdrawal severity by diazepam (Table 2). Error bars represent SEM. Representative photomicrographs of the DG (right) show the increased BrdU + cells along the granule cell layer $(\mathrm{GCL})$ and SGZ border in both alcohol-treated groups when compared with controls. Veh, Vehicle. Scale bar, $100 \mu \mathrm{m} .{ }^{*} p<0.05$.

proliferation occurs at $7 \mathrm{~d}$ of abstinence. Although compensatory changes in the NMDAR may occur from chronic alcohol inhibition of receptor function (Chandler et al., 1998), the observation of increased cell proliferation at day 7 of abstinence is not consistent with a direct effect of alcohol on NMDAR regulation of adult neurogenesis.

Cell death also regulates adult neurogenesis and occurs with chronic alcohol exposure. Studies demonstrate that cell death, ischemic, traumatic brain injury, or experimentally induced, results in compensatory neurogenesis (Cameron et al., 1995; Gould and Tanapat, 1997; Kuhn et al., 2001). Indeed, chronic binge ethanol produces cell death in similar regions: the DG, entorhinal cortex, and cortical areas (Collins et al., 1996; Crews et al., 2000; Obernier et al., 2002). However, in these other models, increased cell proliferation is observed at the time of neurodegeneration, whereas neurodegeneration peaks during the fourth day of chronic binge ethanol treatment (Obernier et al., 2002), a time at which cell proliferation was decreased (Fig. 1). Increased cell proliferation is also observed for up to 2 weeks after ischemia or seizures (Parent et al., 1997; Liu et al., 1998), although we observed a transient increase at 1 week. Ischemia and seizures also produced increased cell proliferation in the SVZ, an effect not observed here (Jin et al., 2001; Parent et al., 2002). Also, protection from ischemic cell loss failed to reverse the increases in cell

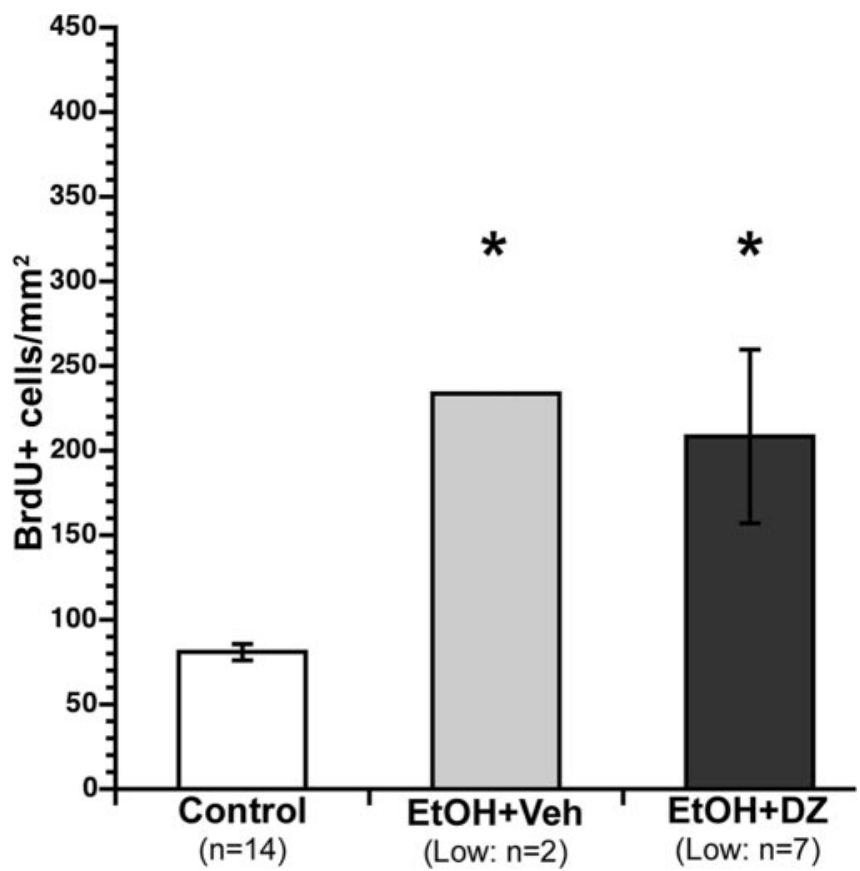

Figure 7. Increased cell proliferation in low withdrawal symptom rats despite few or no withdrawal symptoms. Using the classifications of Majchrowicz (1975) to separate low withdrawal behavior rats shows that BrdU labeling of cell proliferation remained increased even in those animals with little to no overt withdrawal symptoms. The twofold increase in cell proliferation in rats without withdrawal symptoms from both ethanol-exposed groups, ethanol plus vehicle (EtOH + Veh) and ethanol plus diazepam (EtOH + DZ), suggests that alcohol dependence and not withdrawal underlies the burst in cell proliferation at day 7 of abstinence. Error bars represent SEM. ${ }^{*} p<0.05$.

proliferation (Liu et al., 1998), which suggests that for some conditions, such as chronic alcohol, signals elicited by the damaging event and not necessarily the resulting cell death trigger compensatory neurogenesis.

Neurotrophin signaling via cAMP-mediated gene transcription is one such pathway that may be altered by chronic alcohol. Multiple laboratories report that alcohol dependence and withdrawal affect the phosphorylation and activity of cAMP response element binding proteins (CREB) (Pandey et al., 1999, 2001; Bison and Crews, 2003). Specifically, phosphorylated CREB is increased $3 \mathrm{~d}$ after chronic binge ethanol exposure (Bison and Crews, 2003). Recent work has established a role for CREB activity in cell proliferation and cell survival (Nakagawa et al., 2002; Zhu et al., 2004); thus, our previous results are consistent with increased CREB activation contributing to the ethanol-induced increases in cell proliferation at day 7 .

The functional implications of compensatory neurogenesis during abstinence are intriguing but remain speculative until the function of adult neurogenesis is better understood. Adult-born neurons may contribute to hippocampal learning and memory processes and regulation of mood (van Praag et al., 1999b; Shors et al., 2001; Drapeau et al., 2003; Santarelli et al., 2003; Kempermann et al., 2004). Specifically, learning increases neurogenesis 
(Gould et al., 1999), and inhibition of neurogenesis disrupts associative learning (Shors et al., 2001). Abstinent alcoholics show improved cognitive function and a regrowth of brain degeneration within a few months of abstinence from alcohol (Carlen et al., 1978; Pfefferbaum, 1995; Sullivan et al., 2000a,b). Indeed, we found increased neurogenesis 5 weeks after ethanol administration, an effect consistent with the recovery of brain volume and improvements in cognitive function seen in abstinent alcoholics. Previous work assumed that regeneration was attributable to glial regeneration or changes in plasticity (Harper, 1998); thus, this is the first observation of a neuronal regrowth during abstinence after chronic alcohol exposure.

However, alcoholics do not completely recover cognitive abilities nor brain volumes (Eckardt and Martin, 1986; Parsons, 1993), and increased neurogenesis may not improve brain function (Kempermann et al., 2004). In models of epilepsy and stroke, neurogenesis increases several days after the insult, although newborn cells do not restore the granule cell layer to its prelesion state. It has been suggested that aberrant neurogenesis contributes to prolonged neuropathology after seizures (Parent and Lowenstein, 2002; Kempermann et al., 2004). The increased neurogenesis observed here appears in normal locations along the SGZ, but it is not clear whether these new neurons are incorporated appropriately to improve function. Additional studies on the basic role of adult neurogenesis in brain function, and how increased neurogenesis found during abstinence contribute to brain changes associated with alcoholic recovery, are required to fully understand the functional implications of increased neurogenesis during abstinence.

In summary, ethanol has distinct effects on neurogenesis during intoxication and compensatory increases in neurogenesis after alcohol dependence. These dynamic changes in neurogenesis may finally explain discrepancies in the alcoholic neuropathology literature, because time in abstinence clearly determines whether alcohol has produced an inhibition or promotion of neurogenesis. These data further contribute to a growing body of evidence on the role of structural plasticity in drug abuse and other psychiatric disorders (Abrous et al., 2002; Eisch, 2002). As future work elucidates the role of adult neurogenesis to brain function, we will further understand the contribution of altered neurogenesis to cognitive dysfunctions associated with neurodegenerative and psychiatric disorders such as chronic alcoholism.

\section{References}

Aaronson LM, Hinman DJ, Okamoto M (1982) Effects of diazepam on ethanol withdrawal. J Pharmacol Exp Ther 221:319-325.

Abrous DN, Adriani W, Montaron MF, Aurousseau C, Rougon G, Le Moal M, Piazza PV (2002) Nicotine self-administration impairs hippocampal plasticity. J Neurosci 22:3656-3662.

Agartz I, Momenan R, Rawlings RR, Kerich MJ, Hommer DW (1999) Hippocampal volume in patients with alcohol dependence. Arch Gen Psychiatry $56: 356-363$.

Altman J, Das GD (1965) Autoradiographic and histological evidence of postnatal hippocampal neurogenesis in rats. J Comp Neurol 124:319-335.

Armstrong RJ, Barker RA (2001) Neurodegeneration: a failure of neuroregeneration? Lancet 358:1174-1176.

Bengochea O, Gonzalo LM (1990) Effect of chronic alcoholism on the human hippocampus. Histol Histopathol 5:349-357.

Bison S, Crews F (2003) Alcohol withdrawal increases neuropeptide Y immunoreactivity in rat brain. Alcohol Clin Exp Res 27:1173-1183.

Bone GH, Majchrowicz E, Martin PR, Linnoila M, Nutt DJ (1989) A comparison of calcium antagonists and diazepam in reducing ethanol withdrawal tremors. Psychopharmacology 99:386-388.

Brandt J, Butters N, Ryan C, Bayog R (1983) Cognitive loss and recovery in long-term alcohol abusers. Arch Gen Psychiatry 40:435-442.
Brown JP, Couillard-Despres S, Cooper-Kuhn CM, Winkler J, Aigner L, Kuhn HG (2003) Transient expression of doublecortin during adult neurogenesis. J Comp Neurol 467:1-10.

Cameron HA, Gould E (1994) Adult neurogenesis is regulated by adrenal steroids in the dentate gyrus. Neuroscience 61:203-209.

Cameron HA, McKay RD (2001) Adult neurogenesis produces a large pool of new granule cells in the dentate gyrus. J Comp Neurol 435:406-417.

Cameron HA, McEwen BS, Gould E (1995) Regulation of adult neurogenesis by excitatory input and NMDA receptor activation in the dentate gyrus. J Neurosci 15:4687-4692.

Carlen PL, Wortzman G, Holgate RC, Wilkinson DA, Rankin JC (1978) Reversible cerebral atrophy in recently abstinent chronic alcoholics measured by computed tomography scans. Science 200:1076-1078.

Chandler LJ, Harris RA, Crews FT (1998) Ethanol tolerance and synaptic plasticity. Trends Pharmacol Sci 19:491-495.

Collins MA, Corse TD, Neafsey EJ (1996) Neuronal degeneration in rat cerebrocortical and olfactory regions during subchronic "binge" intoxication with ethanol: possible explanation for olfactory deficits in alcoholics. Alcohol Clin Exp Res 20:284-292.

Crews FT, Braun CJ, Hoplight B, Switzer III RC, Knapp DJ (2000) Binge ethanol consumption causes differential brain damage in young adolescent rats compared with adult rats. Alcohol Clin Exp Res 24:1712-1723.

Crews FT, Miller MW, Ma W, Nixon K, Zawada M, Zahkari S (2003) Neural stem cells and alcohol. Alcohol Clin Exp Res 27:324-335.

Crews FT, Nixon K, Wilke MB (2004) Exercise reverses ethanol inhibition of neural stem cell proliferation. Alcohol 33:1-9.

Dahchour A, De Witte P (1999) Effect of repeated ethanol withdrawal on glutamate microdialysate in the hippocampus. Alcohol Clin Exp Res 23:1698-1703.

Deisseroth K, Singla S, Toda H, Monje M, Palmer TD, Malenka RC (2004) Excitation-neurogenesis coupling in adult neural stem/progenitor cells. Neuron 42:535-552.

De Witte P, Pinto E, Ansseau M, Verbanck P (2003) Alcohol and withdrawal: from animal research to clinical issues. Neurosci Biobehav Rev 27:189-197.

Drapeau E, Mayo W, Aurousseau C, Le Moal M, Piazza PV, Abrous DN (2003) Spatial memory performances of aged rats in the water maze predict levels of hippocampal neurogenesis. Proc Natl Acad Sci USA 100:14385-14390.

Eckardt MJ, Martin PR (1986) Clinical assessment of cognition in alcoholism. Alcohol Clin Exp Res 10:123-127.

Eisch AJ (2002) Adult neurogenesis: implications for psychiatry. Prog Brain Res 138:315-342.

Eisch AJ, Barrot M, Schad CA, Self DW, Nestler EJ (2000) Opiates inhibit neurogenesis in the adult rat hippocampus. Proc Natl Acad Sci USA 97:7579-7584.

Eriksson PS, Perfilieva E, Bjork-Eriksson T, Alborn AM, Nordborg C, Peterson DA, Gage FH (1998) Neurogenesis in the adult human hippocampus. Nat Med 4:1313-1317.

Gleeson JG, Lin PT, Flanagan LA, Walsh CA (1999) Doublecortin is a microtubule-associated protein and is expressed widely by migrating neurons. Neuron 23:257-271.

Gould E, Tanapat P (1997) Lesion-induced proliferation of neuronal progenitors in the dentate gyrus of the adult rat. Neuroscience 80:427-436.

Gould E, Beylin A, Tanapat P, Reeves A, Shors TJ (1999) Learning enhances adult neurogenesis in the hippocampal formation. Nat Neurosci 2:260-265.

Grant BF, Dawson DA, Stinson FS, Chou SP, Dufour MC, Pickering RP (2004) The 12-month prevalence and trends in DSM-IV alcohol abuse and dependence: United States, 1991-1992 and 2001-2002. Drug Alcohol Depend 74:223-234.

Hall W, Zador D (1997) The alcohol withdrawal syndrome. Lancet 349:1897-1900.

Harper C (1998) The neuropathology of alcohol-specific brain damage, or does alcohol damage the brain? J Neuropathol Exp Neurol 57:101-110.

Herrera DG, Yague AG, Johnsen-Soriano S, Bosch-Morell F, ColladoMorente L, Muriach M, Romero FJ, Garcia-Verdugo JM (2003) Selective impairment of hippocampal neurogenesis by chronic alcoholism: protective effects of an antioxidant. Proc Natl Acad Sci USA 100:7919-7924.

Jerrells JR, Marietta CA, Weight FF, Eckardt MJ (1990) Effect of adrenalec- 
tomy on ethanol-associated immunosuppression. Int J Immunopharmacol 12:435-442.

Jin K, Minami M, Lan JQ, Mao XO, Batteur S, Simon RP, Greenberg DA (2001) Neurogenesis in dentate subgranular zone and rostral subventricular zone after focal cerebral ischemia in the rat. Proc Natl Acad Sci USA 98:4710-4715.

Kee N, Sivalingam S, Boonstra R, Wojtowicz JM (2002) The utility of Ki-67 and $\mathrm{BrdU}$ as proliferative markers of adult neurogenesis. J Neurosci Methods 115:97-105.

Kempermann G, Gast D, Kronenberg G, Yamaguchi M, Gage FH (2003) Early determination and long-term persistence of adult-generated new neurons in the hippocampus of mice. Development 130:391-399.

Kempermann G, Wiskott L, Gage FH (2004) Functional significance of adult neurogenesis. Curr Opin Neurobiol 14:186-191.

Knapp DJ, Crews FT (1999) Induction of cyclooxygenase-2 in brain during acute and chronic ethanol treatment and ethanol withdrawal. Alcohol Clin Exp Res 23:633-643.

Knapp DJ, Saiers JA, Pohorecky LA (1993) Observations of novel behaviors as indices of ethanol withdrawal-induced anxiety. Alcohol Alcohol Suppl 2:489-493.

Kuhn HG, Dickinson-Anson H, Gage FH (1996) Neurogenesis in the dentate gyrus of the adult rat: age-related decrease of neuronal progenitor proliferation. J Neurosci 16:2027-2033.

Kuhn HG, Jurgen W, Kempermann G, Thal LJ, Gage FH (1997) Epidermal growth factor and fibroblast growth factor-2 have different effects on neural progenitors in the adult rat brain. J Neurosci 17:5820-5829.

Kuhn HG, Palmer TD, Fuchs E (2001) Adult neurogenesis: a compensatory mechanism for neuronal damage. Eur Arch Psychiatry Clin Neurosci 251:152-158.

Laakso MP, Vaurio O, Savolainen L, Repo E, Soininen H, Aronen HJ, Tiihonen J (2000) A volumetric MRI study of the hippocampus in type 1 and 2 alcoholism. Behav Brain Res 109:177-186.

Lee J, Duan W, Mattson MP (2002) Evidence that brain-derived neurotrophic factor is required for basal neurogenesis and mediates, in part, the enhancement of neurogenesis by dietary restriction in the hippocampus of adult mice. J Neurochem 82:1367-1375.

Liu J, Solway K, Messing RO, Sharp FR (1998) Increased neurogenesis in the dentate gyrus after transient global ischemia in gerbils. J Neurosci 18:7768-7778.

Lois C, Alvarez-Buylla A (1993) Proliferating subventricular zone cells in the adult mammalian forebrain can differentiate into neurons and glia. Proc Natl Acad Sci USA 90:2074-2077.

Lukoyanov NV, Brandão F, Cadete-Leite A, Madeira MD, Paula-Barbosa MM (2000) Synaptic reorganization in the hippocampal formation of alcohol-fed rats may compensate for functional deficits related to neuronal loss. Alcohol 20:139-148.

Majchrowicz E (1975) Induction of physical dependence upon ethanol and the associated behavioral changes in rats. Psychopharmacologia 43:245-254.

Mhatre MC, McKenzie SE, Gonzalez LP (2001) Diazepam during prior ethanol withdrawals does not alter seizure susceptibility during a subsequent withdrawal. Pharmacol Biochem Behav 68:339-346.

Nakagawa S, Kim JE, Lee R, Malberg JE, Chen J, Steffen C, Zhang YJ, Nestler EJ, Duman RS (2002) Regulation of neurogenesis in adult mouse hippocampus by cAMP and the cAMP response element-binding protein. J Neurosci 22:3673-3682.

Nixon K, Crews FT (2002) Binge ethanol exposure decreases neurogenesis in adult rat hippocampus. J Neurochem 83:1087-1093.

Obernier JA, Bouldin TW, Crews FT (2002) Binge ethanol exposure in adult rats causes necrotic cell death. Alcohol Clin Exp Res 26:547-557.

Palmer TD, Takahashi J, Gage FH (1997) The adult rat hippocampus contains primordial neural stem cells. Mol Cell Neurosci 8:389-404.

Pandey SC, Zhang D, Mittal N, Nayyar D (1999) Potential role of the gene transcription factor cyclic AMP-responsive element binding protein in ethanol withdrawal-related anxiety. J Pharmacol Exp Ther 288:866-878.
Pandey SC, Roy A, Mittal N (2001) Effects of chronic ethanol intake and its withdrawal on the expression and phosphorylation of the creb gene transcription factor in rat cortex. J Pharmacol Exp Ther 296:857-868.

Parent JM, Lowenstein DH (2002) Seizure-induced neurogenesis: are more new neurons good for an adult brain? Prog Brain Res 135:121-131.

Parent JM, Yu TW, Leibowitz RT, Geschwind DH, Sloviter RS, Lowenstein DH (1997) Dentate granule cell neurogenesis is increased by seizures and contributes to aberrant network reorganization in the adult rat hippocampus. J Neurosci 17:3727-3738.

Parent JM, Vexler ZS, Gong C, Derugin N, Ferriero DM (2002) Rat forebrain neurogenesis and striatal neuron replacement after focal stroke. Ann Neurol 52:802-813.

Parsons OA (1993) Impaired neuropsychological cognitive functioning in sober alcoholics. In: Alcohol-induced brain damage (Hunt WA, Nixon SJ, eds), pp 173-194. Rockville, MD: National Institutes of Health.

Penland S, Hoplight B, Obernier J, Crews FT (2001) The effects of nicotine on ethanol dependence and brain damage. Alcohol 24:45-54.

Pfefferbaum A (1995) Longitudinal changes in magnetic resonance imaging brain volumes in abstinent and relapsed alcoholics. Alcohol Clin Exp Res 19:1177-1191.

Popken GJ, Farel PB (1997) Sensory neuron number in neonatal and adult rats estimated by means of stereologic and profile-based methods. J Comp Neurol 386:8-15.

Rice AC, Bullock MR, Shelton KL (2004) Chronic ethanol consumption transiently reduces adult neural progenitor cell proliferation. Brain Res 1011:94-98.

Riihioja P, Jaatinen P, Oksanen H, Haapalinna A, Heinonen E, Hervonen A (1997) Dexmedetomidine, diazepam, and propranolol in the treatment of ethanol withdrawal symptoms in the rat. Alcohol Clin Exp Res 21:804-808.

Rossetti ZL, Carboni S (1995) Ethanol withdrawal is associated with increased extracellular glutamate in the rat striatum. Eur J Pharmacol 283:177-183.

Santarelli L, Saxe M, Gross C, Surget A, Battaglia F, Dulawa S, Weisstaub N, Lee J, Duman R, Arancio O, Belzung C, Hen R (2003) Requirement of hippocampal neurogenesis for the behavioral effects of antidepressants. Science 301:805-809.

Scholzen T, Gerdes J (2000) The Ki-67 protein: from the known and the unknown. J Cell Physiol 182:311-322.

Shors TJ, Miesegaes G, Beylin A, Zhao M, Rydel T, Gould E (2001) Neurogenesis in the adult is involved in the formation of trace memories. Nature 410:372-376.

Sullivan EV, Marsh L, Mathalon DH, Lim KO, Pfefferbaum A (1995) Anterior hippocampal volume deficits in nonamnesic, aging chronic alcoholics. Alcohol Clin Exp Res 19:110-122.

Sullivan EV, Rosenbloom MJ, Lim KO, Pfefferbaum A (2000a) Longitudinal changes in cognition, gait, and balance in abstinent and relapsed alcoholic men: relationships to changes in brain structure. Neuropsychology 14:178-188.

Sullivan EV, Rosenbloom MJ, Pfefferbaum A (2000b) Pattern of motor and cognitive deficits in detoxified alcoholic men. Alcohol Clin Exp Res 24:611-621.

van Praag H, Kempermann G, Gage FH (1999a) Running increases cell proliferation and neurogenesis in the adult mouse dentate gyrus. Nat Neurosci 2:266-270.

van Praag H, Christie BR, Sejnowski TJ, Gage FH (1999b) Running enhances neurogenesis, learning, and long-term potentiation in mice. Proc Natl Acad Sci USA 96:13427-13431.

Walker DW, Barnes DE, Zornetzer SF, Hunter BE, Kubanis P (1980) Neuronal loss in hippocampus induced by prolonged ethanol consumption in rats. Science 209:711-713.

Zhu DY, Lau L, Liu SH, Wei JS, Lu YM (2004) Activation of cAMPresponse-element-binding protein (CREB) after focal cerebral ischemia stimulates neurogenesis in the adult dentate gyrus. Proc Natl Acad Sci USA 101:9453-9457. 